\title{
CHRONIC CONSTRICTIVE PERICARDITIS COMBINED WITH HYPOPROTEINAEMIA
}

\author{
BY \\ F. KUIPERS \\ From the Paediatric Clinic of the University of Amsterdam, the Netherlands
}

(RECEIVED FOR PUBLICATION DECEMBER 24, 1954)

Constrictive pericarditis usually affects males in the third and fourth decades of life (Paul, Castleman and White, 1948; Chambliss, Jaruszewski, Brofman, Martin and Feil, 1951), but is rare under the age of 10. Rothstein (1934) collected 34 cases from the literature in children up to 15 years old, who had been operated on, but only 12 were younger than 10 . More reports have appeared since, but the children are now usually included in large series of patients who have undergone an operation. It is often impossible to select the children from those series and thus to establish any special features that might occur in childhood, for instance hypoproteinaemia, as has been suggested by McKusick (1952). The rarity of the disease in children, together with the difficulties we originally had in making the diagnosis, have prompted the following case report.

\section{Case Report}

On March 3, 1954, a 7-year-old boy was referred to the Children's Clinic for investigation of hypoproteinaemic oedema and ascites. He was the eighth of 11 children. The family history contributed nothing but the boy had been treated badly during the first six months of life and a state of malnutrition had developed. He was then brought up by step-parents on a farm and he had not been ill since.

An inguinal hernia was operated upon in February, 1953. Much fluid had appeared from the abdominal

TABLE 1

LEVEL OF BLOOD PROTEINS (METHOD OF HOWE) ON VARIOUS ДDATES

\begin{tabular}{|c|c|c|c|c|c|c|c|c|c|}
\hline Date & $\begin{array}{c}9 / 8 \\
1953\end{array}$ & 9/17 & $9 / 29$ & $10 / 19$ & $\begin{array}{l}1 / 28 \\
1954\end{array}$ & $2 / 23$ & $3 / 3$ & $4 / 14$ & $7 / 8$ \\
\hline $\begin{array}{l}\text { Albumin } \\
\text { Globulin }\end{array}$ & $\begin{array}{l}3.54 \\
0.96\end{array}$ & $\begin{array}{l}3 \cdot 3 \\
1.9\end{array}$ & $\begin{array}{l}3 \cdot 17 \\
1.93\end{array}$ & $\begin{array}{l}3.08 \\
1.62\end{array}$ & \begin{tabular}{|l|}
2.58 \\
1.42
\end{tabular} & $\begin{array}{l}2.63 \\
1.72 \\
\end{array}$ & $\begin{array}{l}2 \cdot 53 \\
1 \cdot 37\end{array}$ & $\begin{array}{l}2.45 \\
0.92\end{array}$ & $\begin{array}{l}4.64 \\
1.4\end{array}$ \\
\hline Total & $4 \cdot 5$ & $5 \cdot 2$ & $5 \cdot 1$ & $4 \cdot 7$ & $4 \cdot 0$ & $4 \cdot 35$ & 3.9 & $\overline{3 \cdot 37}$ & $\overline{6.04}$ \\
\hline
\end{tabular}

Electrophoretic fractionation according to the Tiselius method: albumin 19.32, a-ghobulin $5.91, \beta$-globulin $6.54, \gamma$-globulin $3.22 \mathrm{~g} / 1$. Total serum proteins $=34 \mathrm{~g}$. per 1 . cavity. The boy had made an uneventful recovery. During the summer he had measles and chickenpox, and afterwards cedema of the face and feet was noted. His appetite decreased and periodically he had loose stools. During clinical observation elsewhere (August, 1953) an enlarged liver and ascites were found. The blood protein levels were low (Table 1), the cholesterol content of the blood was normal (Table 2) as were the temperature and pulse rate. No protein could be demonstrated in the urine. A series of liver function tests did not show any abnormalities. No tubercle bacilli could be cultured from the ascites. A needle biopsy of the liver did not show histological abnormalities. The tuberculin test of the skin was negative. The boy now had a ravenous appetite. His condition improved although the blood protein levels did not change much, and even showed a

TABLE 2

BIOCHEMICAL DATA AND LIVER FUNCTION TESTS ON VARIOUS DATES

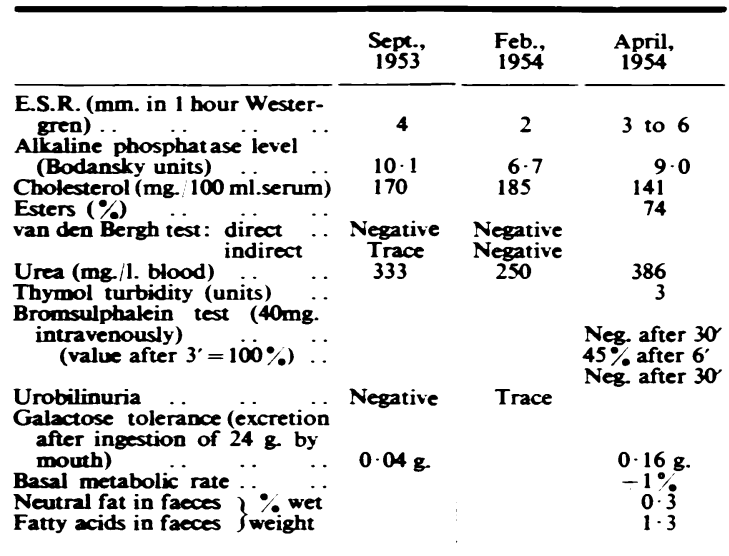

Blood sugar levels $(\mathrm{mg} / 100 \mathrm{ml}$.) fasting and at various times after the ingestion by mouth of glucose and fructose

\begin{tabular}{|c|c|c|c|c|c|c|}
\hline & & 0 & $\underset{30}{\text { After }}$ & 60 & 90 & $150^{\circ}$ \\
\hline $\begin{array}{l}30.0 \text { g. glucose } \\
36.5 \text { \&. fructose }\end{array}$ & $\begin{array}{l}. \\
\cdots\end{array}$ & $\begin{array}{l}119 \\
105\end{array}$ & $\begin{array}{l}179 \\
126\end{array}$ & $\begin{array}{l}189 \\
133\end{array}$ & $\begin{array}{l}165 \\
121\end{array}$ & $\begin{array}{r}93 \\
122\end{array}$ \\
\hline
\end{tabular}




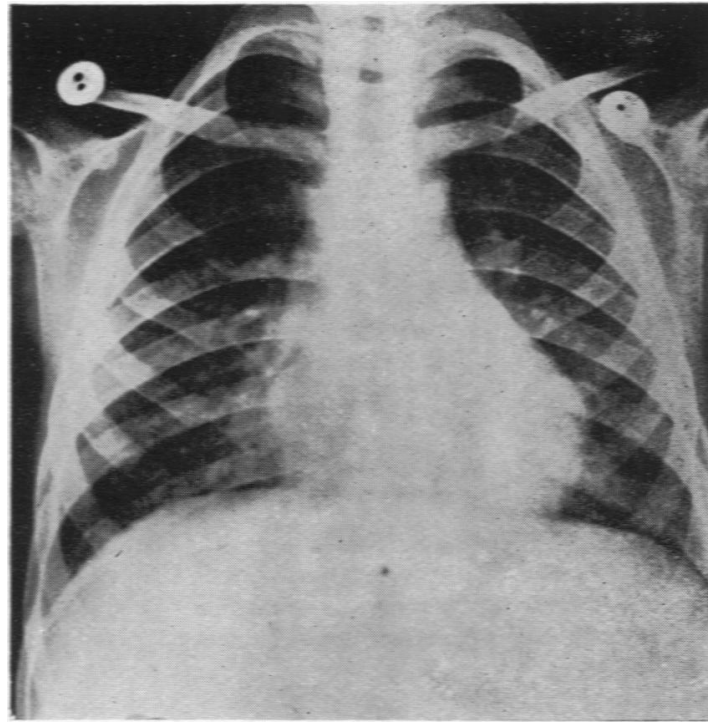

Fig. 1.-Radiograph of the heart before operation.

tendency to decrease (Table 1). He was treated with a diet poor in salt, but rich in proteins plus methionine and vitamin B complex and liver injections. Shortly after a purulent otitis the ascites again increased considerably and he was readmitted at the end of January, 1954 Biochemical results were as before, and he was transferred to the Children's Clinic for further investigation.

We found a short, stubby boy (somatic development about 5 years old) with a considerably enlarged chest circumference similar to that of a child of 11 years. His weight was $21 \mathrm{~kg}$. He was in no apparent distress but on exertion easily became dyspnoeic. No cyanosis was present, the respiration rate being about 20 per minute. His face was puffy and slight oedema was present around the eyelids. The heart sounds were normal. The liver edge was felt $5 \mathrm{~cm}$. below the costal margin and the presence of free fluid in the abdominal cavity could easily be demonstrated. Compared with slight oedema in the legs the amount of ascites was considerable. Blood pressure measured $95 / 60 \mathrm{~mm}$. of mercury, and engorgement of the neck veins with pulsations of a level about $4 \mathrm{~cm}$. above the angle of the sternum indicated an increased venous pressure. No protein or other abnormality could be demonstrated in $\boldsymbol{f}$ the urine. Urobilinuria was sometimes increased.

Chronic constrictive pericarditis was suspected. The heart seemed to be somewhat enlarged to the left (Fig. 1) but pulsations were thought to be normal / during fluoroscopy and no deposits of calcium could be seen. The radiokymograph demonstrated fair pulsations of the left border of the heart (Fig. 2). Although the right border did not pulsate this was not accepted as evidence of constrictive pericarditis, because the auricles generally do not show evident pulsations on a kymograph. An electrocardiogram demonstrated right axis deviation in the standard limb leads and severe right axis strain in the $V$ leads. The height of the excursions was thought to be normal, although in several leads the $P$ and the $T$ waves could barely be distinguished (Fig. 3).

The diuresis measured between 200 and $400 \mathrm{ml}$. per day, while the fluid intake was free (about 700 to $1,000 \mathrm{ml}$. per day). The specific gravity of the urine was 1,020 or more. The daily output of chlorides was less than $5 \mathrm{mEq}$., but the salt in the diet was restricted.

During the first fortnight of observation the level of the pulsations in the veins of the neck decreased gradually until it corresponded with the level of the angle of Louis measured by the method of Borst and Molhuysen (1952). The body weight remained fairly constant and no change occurred in the size of the liver nor in the amount of the ascites. In the meantime a series of liver function tests gave normal results, including two bromsulphthalein tests (Table 2). Also the tuberculin test with $1 \mathrm{mg}$. of old tuberculin was negative, as were serological tests for syphilis.

So far we had not obtained a satisfactory explanation for the syndrome of oedema, enlargement of the liver, ascites, increased venous pressure and hypoproteinaemia. Malnutrition, the nephrotic syndrome or cirrhosis of the liver could be ruled out. In spite of the changes in the electrocardiogram and the increased venous pressure heart failure seemed unlikely, because two bromsulphalein tests and the circulation time were normal. No evidence of chronic constrictive pericarditis had been found on the $x$-ray pictures.

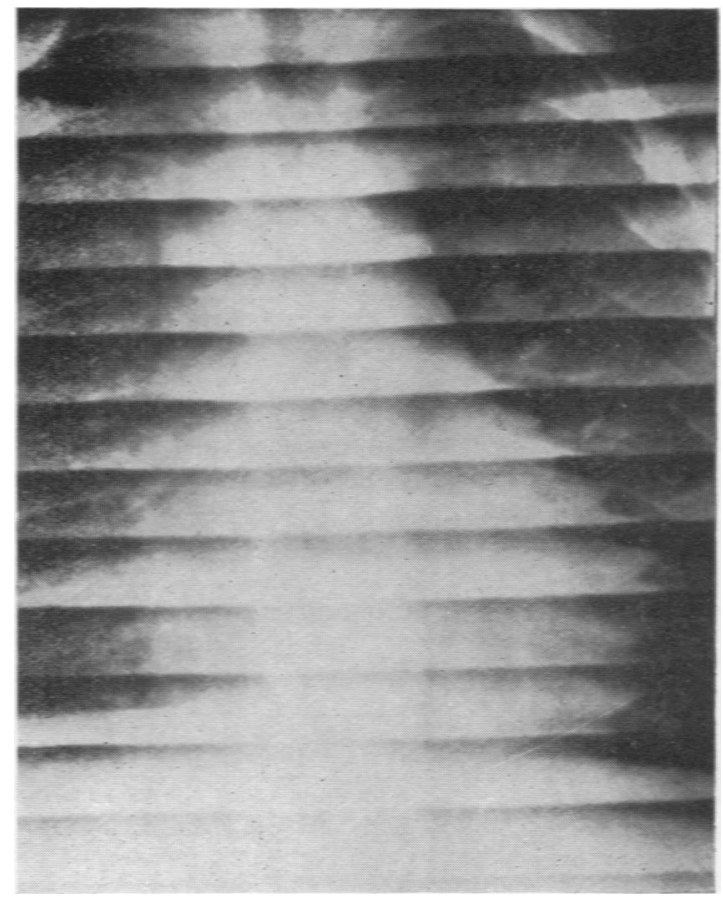

FiG. 2.-Radiokymograph before operation. 


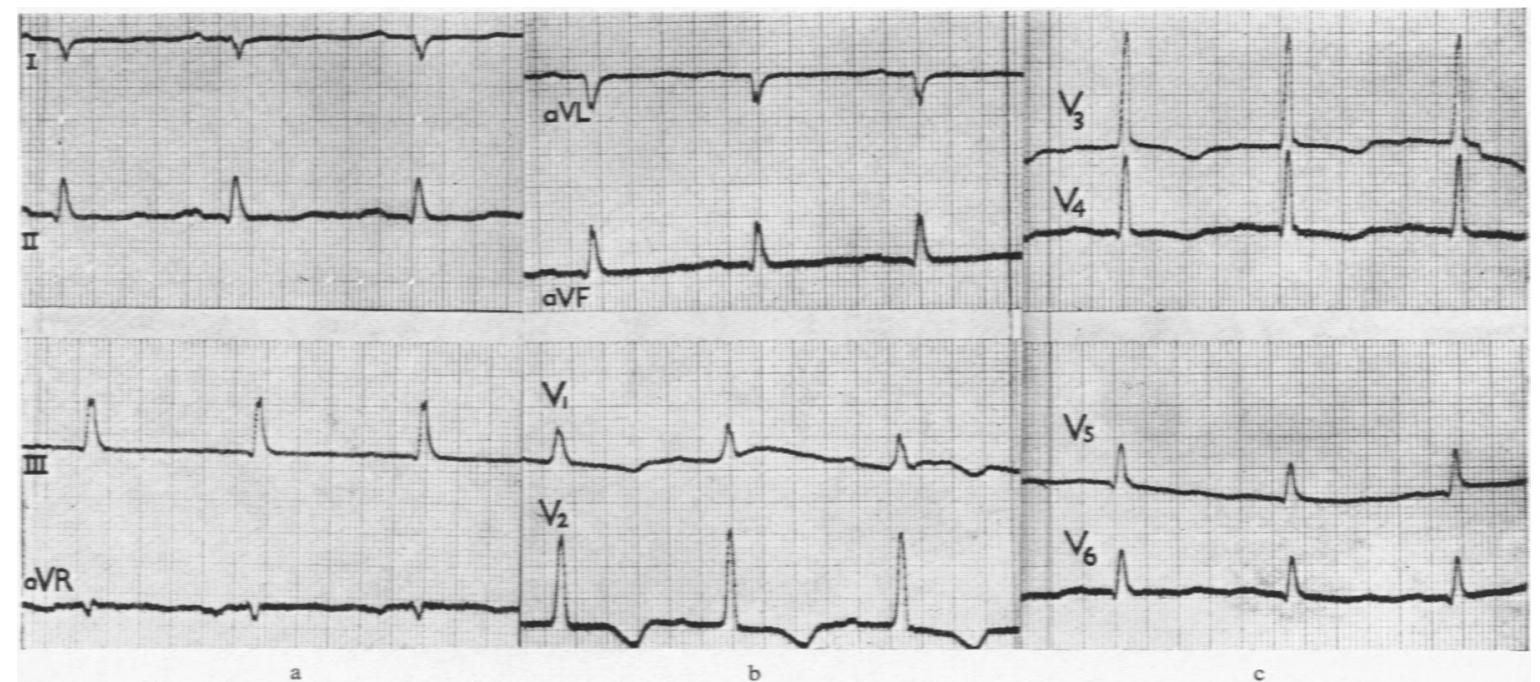

FKG. 3a-c.-Electrocardiogram showing right ventricular strain.

We first decided to investigate the effect of digitalis on the diuresis and on the increased venous pressure. The diuresis increased to 550 and $700 \mathrm{ml}$. during the first two days of digitalization with the equivalent of $100 \mathrm{mg}$. digitalis per day. However, the backward failure of the right heart got worse. The venous pressure rose to more than $5 \mathrm{~cm}$. above the sternal angle (Lewis, 1930: Borst, 1943; Borst and Molhuysen, 1952) orthopnoea and moist râles indicated acute congestion of the lungs. An inconstant triple rhythm was heard and a paradoxical filling of the pulse was noted. The temperature then suddenly rose to $39 \cdot 6^{\circ} \mathrm{C}$. but with the aid of penicillin and the withdrawal of digitalis the boy managed to weather this period of severe congestive heart failure with respiratory infection. The increased venous pressure dropped gradually. Ten days later the improvement was such that catheterization of the heart was possible to obtain further information about the circulatory relations in the heart (Dr. M. L. M. Houben).

The catheter could easily be brought into the branches of the pulmonary artery. No abnormalities were found in the vessels or in the septum of the heart. The pressure curves of the right chambers, however, showed certain peculiarities characteristic of constrictive pericarditis.
These changes were indicated for the first time by Bloomfield, Lauson, Cournand, Breed and Richards (1946), and have been elaborated extensively by Hansen, Eskildsen and Götzsche (1951), Yu, Lovejoy, Joos, Nye and Mahoney (1953) and Tourniaire, Blum, Deyrieux, and Tartulier (1953). They have been aptly summarized by Yu et al. as follows:

'The auricular pressure curve shows a M-or-Wshaped pattern, with two upward and two downward deflections, both failing to reach the base line. The mean pressure in the auricle is moderately elevated. The right ventricular pressure curve shows a slightly elevated systolic pressure and a rapid diastolic dip followed by a high diastolic plateau and high diastolic end-pressure. The ratio of the diastolic end-pressure to systolic pressure is more than one-third. The diastolic plateau is the expression of the diastolic filling defect being the essential haemodynamic changé in constrictive pericarditis. The plateau has disappeared in patients successfully operated.'

When failure of the right ventricle is present in conditions such as stenosis of the pulmonary artery, mitral stenosis or severe emphysema, diastolic end-pressure can be elevated also. Yu et al. investigated 132 patients, but always found the ratio between diastolic end-pressure and systolic pressure to be less than onethird in conditions other than constrictive pericarditis. In our case this ratio varied between onehalf and two-thirds. The pressure curve during 【withdrawal 
of the catheter from the right ventricle is shown in Fig. 4. The pressures in the caval vein and in the right auricle were considerably elevated (maximum 20 , minimum $10 \mathrm{~mm}$. of mercury), while the diastolic pressure in the right ventricle was especially increased (20 to $24 \mathrm{~mm}$.). The fluctuation of the pressure curve in the ventricle increased abnormally during deep respirations (f.i. $40 / 30$ and $18 / 12 \mathrm{~mm}$. respectively), a demonstration of paradoxical filling of the pulse. The oxygen saturation varied between 65 and $70 \%$ in the right heart chambers and in the pulmonary artery. In the 'capillaries' of the lung artery a saturation of $93 \%$ was found. The mean pressure there was rather high (about $20 \mathrm{~mm}$.) and the fluctuations were large. This indicates serious involvement of the left ventricle (Sawyer, Burwell, Dexter, Eppinger, Goodale, Gorlin, Harken and Haynes, 1952), indicating that the surgeon should liberate the left side first (Isaacs, Carter, Noland and Haller, 1952).

In this case cardiac catheterization led us back to the right track again, but we might have made the correct diagnosis earlier had we taken to heart the advice of Barroy and van Heerswynghels (1946), who demonstrated layers of calcium in the pericardium by means of extra hard $x$ rays. By this technique calcium could be demonstrated (Figs. 5 and 6) over the left ventricle in our patient also. The radiokymogram had been thought to show normal pulsations, but perhaps electrokymographic analysis (McKusick, 1952) would have prevented this assumption. Unfortunately no facilities to apply this method were available in this hospital.

In the next two weeks the condition of our patient improved further, the level of the pulsations in the neck

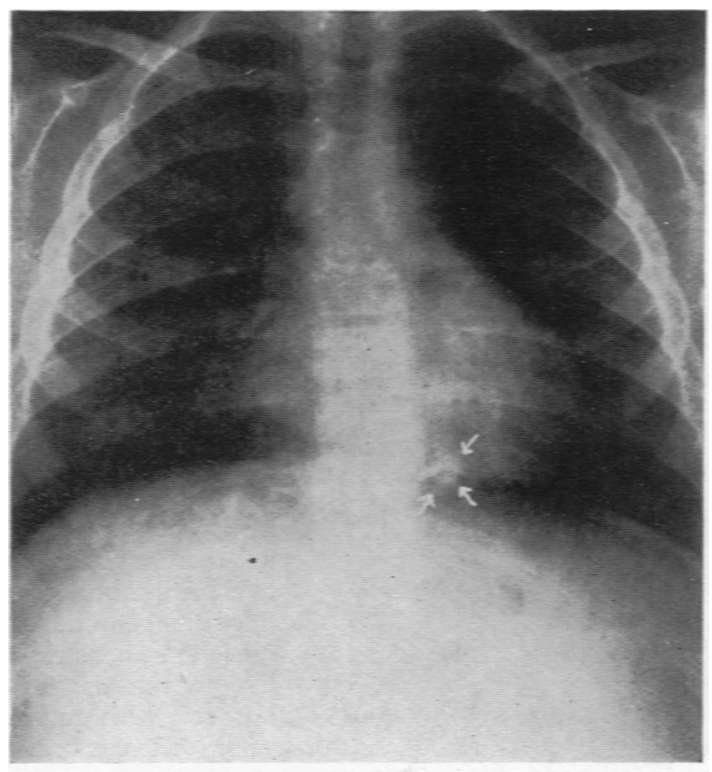

FIG. 5. veins dropping to below the sternal angle. The amount of ascites was plainly diminishing. However, the spontaneous improvement did not continue and the oedema and ascites were again progressing. The effect of a mercurial diuretic was only of very short duration. The only effective treatment was clearly resection of the pericardium. This was performed by Professor I. Boerema on June 14.

After a median incision the sternum was split and a few adhesions between the pericardium and the chest wall were removed. The heart was enveloped by a pergameneous pericardium, that also adhered to the epicardium. The adhesions were easily loosened. First the left ventricle was liberated, then the right ventricle and finally the mouths of the large veins also. Next the myocardium turned out to be covered by a thick new layer of fibrous epicardium. This was also removed for the most part. A small haemorrhage at the level of the auricles was stopped in a few moments. The whole myocardium had become bare, with the exception of a fibrinous cover in the region of the tip of the heart. The pulsations of the heart were visibly improved and the chest wall was closed. The first day after operation the boy was orthopnoeic and he was put into an oxygen tent. Soon his condition improved, the heart action became regular, and he lost the oedema. Also the ascites and the enlargement of the liver disappeared in a few weeks. The QRS waves increased somewhat in height. The volume of the heart increased also, as could be shown by radiographs and fluoroscopy (Fig. 7). Three weeks after the resection of the peri- and epi-cardium the blood proteins had become normal (Table 1). The patient was

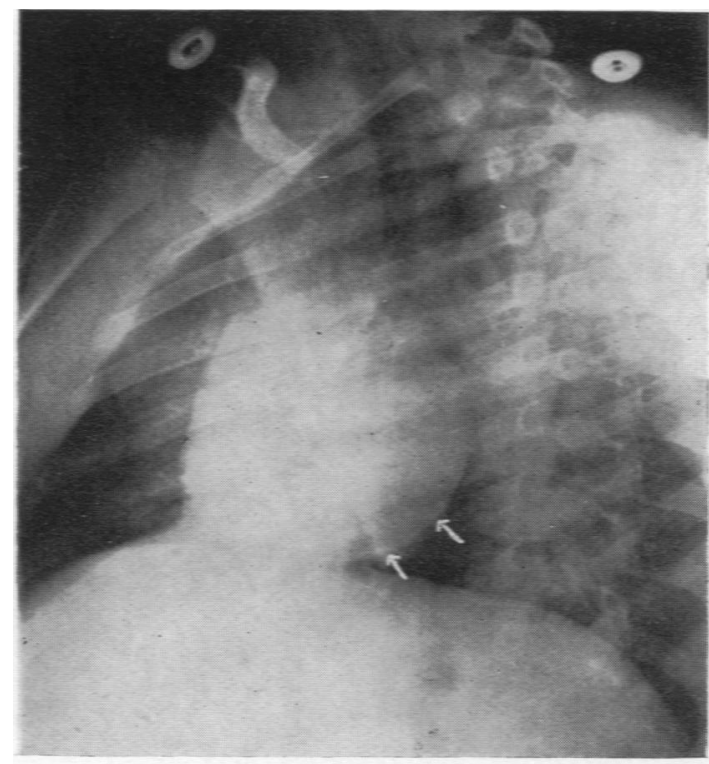

FIG. 6.

Figs. 5 and 6.-Arrows point towards calcium deposits in epicardium. 
discharged in a very much improved condition, the venous pressure being normal (level of the pulsations $3 \mathrm{~cm}$. below the sternal angle).

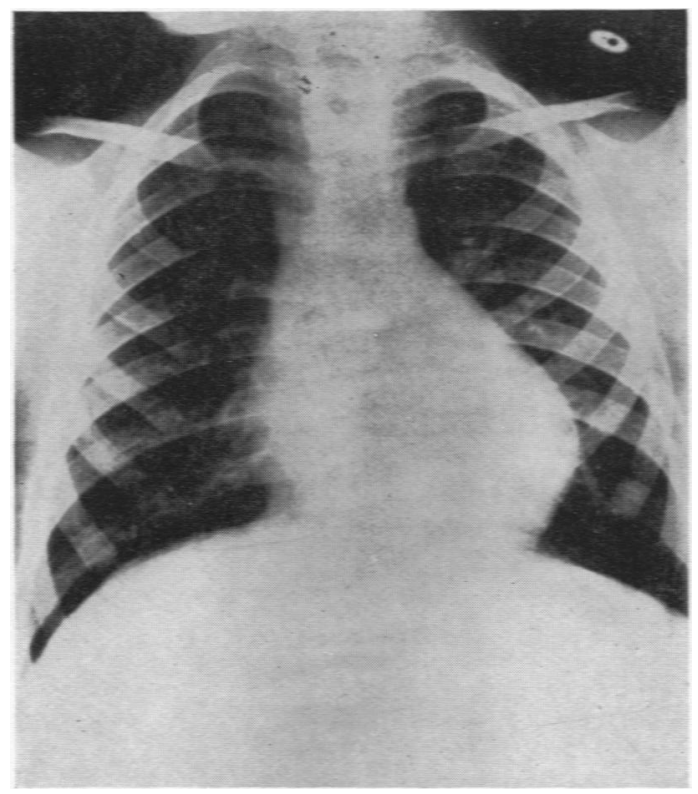

Fig. 7.- Radiograph of the heart after operation. Augmentation in volume (compare with Fig. 1).

\section{Discussion}

The syndrome of constrictive pericarditis is rare, especially in children, although dense, scar-like adhesions of the pericardium are found in 2 to $4 \%$ of all necropsies (Moschcowitz, 1953). Large surveys on diagnosis and treatment have been published during recent years by Holman and Willett (1949), Paul et al. (1948), White, Alexander, Churchill and Sweet (1948) and Chambliss et al. (1951). No special attention has been paid to differences in the syndrome at various ages, but McKusick (1952) mentions the possibility that the association of constrictive pericarditis with hypoproteinaemia might be a special feature in children. In the large series no separate reports are given about children but a few observations (McQuarrie, 1942; Stadler and Stinger, 1941) support this assumption. Moreover the first patient of Barroy and van Heerswynghels (1946) was reported to have a total level of blood proteins of $3 \cdot 74 \%$ (albumin $1.675 \%$ ); this girl was 7 years old. Another girl of 11 had a level of $6.55 \%$ of blood proteins. In McKusick's (1952) series of 20 patients six had a serum albumin level of $3.5 \mathrm{~g}$. per $100 \mathrm{ml}$. or less. All these patients had had the disease from at least the early 'teens. With one exception they were more than 20 years old when they were investigated. These figures do not differ very much from those given by Chambliss et al. (1951), who found an average of $3.46 \mathrm{~g}$. albumin per $100 \mathrm{ml}$. of serum in 39 patients, most of them adults. In 44 of their patients total blood proteins averaged $6.0 \%$, the patients with oedema having an average of $0.5 . \mathrm{g}$. blood proteins less than those without oedema. The degree of hypoalbuminaemia in young children is evidently lower than in adults, even when only the method of Howe is used for fractionation.

A decrease of the level of albumin in the blood has also been shown to occur in heart failure from causes other than constrictive pericarditis (Herrmann, 1946), although this does not always imply that the production of albumin is impaired, because the total volume of plasma is usually considerably increased (Gerbrandy, 1952). The changes in blood volume and in the content of blood proteins in constrictive pericarditis are different from those in other causes of backward failure: the blood volume was only at the upper normal limit in Chambliss's patients and no increase of the level of globulin was present. The circulation time varied between 13 and 45 seconds; in $40 \%$ of the cases it was less than 24 seconds, so it can be normal as it was in our patient ( 8 seconds). This unexpected finding could perhaps be explained by assuming that at least a part of the magnesium sulphate is being pumped through the lungs without delay, the emptying of both ventricles not being materially impaired. The cardiac index in our patient, as cakculated from data obtained during catheterization, measured

$$
\frac{2 \cdot 4}{0 \cdot 73}=3 \cdot 31
$$

per minute per square metre of body surface.

No satisfactory explanation can be given of the hypoproteinaemia in constrictive pericarditis. Apparently the production of albumin in the liver is impaired, but why are no other functions also impaired and why does constrictive pericarditis especially cause hypoproteinaemia, in contrast to other causes of chronic heart failure? The condition is quickly reversible as has been demonstrated in our patient, so it can hardly be due to fibrosis. Niggli (1950) has found a relation between the severity and length of congestive heart failure, the decrease of albumin in the blood and the presence of fibrosis in the liver, but all these patients were adults.

Finally we should like to stress that in our patient the aetiology of the constrictive pericarditis could not be tuberculous, which is at variance with several recent publications (e.g. Andrews, Pickering and Sellors (1948). The tuberculin test with $1 \mathrm{mg}$. of old tuberculin was repeatedly negative, which rules 
out active tuberculosis with certainty. The histological examination of the pericardium gave no further clue as to the aetiology (J. F. Hampe).

Although the triad of Beck (1935)- high venous pressure, ascites and a quiet heart-diagnostic of chronic cardiac compression, was present in our patient, the ordinary investigations, namely, electrocardiography, fluoroscopy, radiokymography and measurement of circulation time did not confirm a tentative diagnosis of constrictive pericarditis. The unfavourable effect of digitalization and the typical changes found during catheterization led our thoughts back to the right diagnosis. Less time would have been lost had we taken the 'hard' $x$-ray pictures earlier. Therefore we wish to stress the importance of this technique, together with catheterization of the heart, in children having hypoproteinaemic oedema, ascites and increased venous pressure, which can be so easily demonstrated in the engorged veins of the neck.

\section{Summary}

A case is presented with constrictive pericarditis in a 7-year-old boy, demonstrating some atypical signs. Hypoproteinaemia and ascites were dominating. No complaints or signs of heart failure were present, with the exception of increased venous pressure, as could be demonstrated in the neck. The radiokymograph showed fair pulsations of the ventricles but the data of the pressure curves from the right auricle, right ventricle and pulmonary artery gave definite evidence of constrictive pericarditis. The presence of calcium in the pericardium could be demonstrated only on pictures taken with 'hard' $x$ rays.
A successful peri- and epicardectomy (nearly total) was done, which was followed by restoration of the blood proteins in three weeks.

The association of hypoproteinaemia and constrictive pericarditis in childhood was commented upon.

I wish to thank Prof. I. Boerema, Prof. S. van Creveld and Dr. H. A. Ph. Hartog for helpful criticism, and G. G. A. Mastenbroek, Ph.D., for advice on the electrophoretic fractionation.

I am further much indebted to Dr. H. L. J. M. Bartels for his cooperation and his permission to use his data.

\section{REFERENCES}

Andrews, G. W. S., Pickering, G. W. and Sellors, T. Holmes (1948). Quart. J. Med., 17, 291.

Barroy, Y. and van Heerswynghels, J. (1946). Brux.-méd., 26. 113. Beck, C. S. (1935). J. Amer. med. Ass., 104, 714.

Borst, J. G. G. (1948). Acta med. scand. Suppl., 207.

Borst, J. G. G. (1948). Acta med. scand. Suppl., 207.

Błoomfield, R. A., Lauson, H. D., Coumand, A., Breed, E. S. and Richards, D. W. Jr. (1946). J. clin. Invest., 25, 639.

Chambliss, J. R., Jaruszewski, E. J., Brofman, B. L., Martin, J. F. and Feil, H. (1951). Circulation, 4, 816

Gerbrandy, J. (1952). Thesis, Amsterdam.

Hansen, A. T., Eskildsen, P. and Götzsche, H. (1951). Circulation, 3. 881 .

Herrmann, G. R. (1946). Ann. Intern. Med., 24, 893.

Holman, E., and Willett, F. (1949). Surg. Gynec. Obstet., 89, 129.

Isaacs, J. P., Carter II, B. Noland and Haller, J. A. Jr. (1952). Bull. Johns Hopk. Hosp., 90, 259.

Lewis, J. (1930). Brit med J. 1, 849.

McKusick, V. A. (1952). Ibid., 90, 3 and 27.

McQuarrie, I. (1942). J.-Lancet, 62, 199.

Moschcowitz E. (1953). J. Amer. med. Ass., 153, 194.

Niggli, S. (1950). Cardiologia, 17. 29.

Paul, O.. Castleman, B. and White, P. D. (1948). Amer. J. med. Sci., 216, 361 .

Rothstein, J. L. (1934). Arch. Pediat., 51, 219 and 288.

Sawyer, C. G., Burwell, C. S., Dexter, L., Eppinger, E. C., Goodale, W. T., Gorlin, R., Harken, D. E. and Haynes, F. W. (1952). Amer. Heart J., 4, 207.

Stadler, H. and Stinger, D. (1941). J. Pediat., 18, 84

Stadler, H. and Stinger, D. (1941). J. Pediat, 18, 84. Arch. Mal. Coeur., 46. 129.

White, P. D., Alexander, F., Churchill, E. D. and Sweet, R. H. (1948). Amer. J. med. Sci., 216, 378

Yu, P. N. G., Lovejoy, F. W., Sr., Joos, H. A., Nye, R. E. Jr. and Mahoney, E. B. (1953). Circulation, 7, 102. 